\title{
The story of plumes: the development of a new conceptual framework for understanding magnetosphere and ionosphere coupling
}

\author{
Mark B. Moldwin, Shasha Zou, and Tom Heine \\ Climate and Space Sciences and Engineering, University of Michigan, Ann Arbor, USA \\ Correspondence to: Mark B. Moldwin (mmoldwin@umich.edu)
}

Received: 29 August 2016 - Revised: 9 November 2016 - Accepted: 26 November 2016 - Published: 21 December 2016

\begin{abstract}
The name "plume" has been given to a variety of plasma structures in the Earth's magnetosphere and ionosphere. Some plumes (such as the plasmasphere plume) represent elevated plasma density, while other plumes (such as the equatorial $\mathrm{F}$ region plume) represent low-density regions. Despite these differences these structures are either directly related or connected in the causal chain of plasma redistribution throughout the system. This short review defines how plumes appear in different measurements in different regions and describes how plumes can be used to understand magnetosphere-ionosphere coupling. The story of the plume family helps describe the emerging conceptual framework of the flow of high-density-low-latitude ionospheric plasma into the magnetosphere and clearly shows that strong two-way coupling between ionospheric and magnetospheric dynamics occurs not only in the high-latitude auroral zone and polar cap but also through the plasmasphere. The paper briefly reviews, highlights and synthesizes previous studies that have contributed to this new understanding.
\end{abstract}

Keywords. Ionosphere (ionosphere-magnetosphere interactions) - magnetospheric physics (magnetosphereionosphere interactions; plasmasphere)

\section{Introduction}

There are three main classes of plumes that are described in the literature: plasmaspheric plumes observed in the inner magnetosphere, storm-enhanced density (SED) plumes observed in the midlatitude ionosphere (primarily the topside ionosphere) and equatorial plumes (also called bubbles, bite-outs or depletions) observed in the $\mathrm{F}$ region equatorial ionosphere and associated with spread F. Plasmaspheric and SED plumes are defined as high-density regions, while equatorial plumes are low-density regions. Each of these phenomena was discovered by multiple diagnostic techniques independently. However, over the last 15 or so years they have been connected to each other by using multi-instrument studies (primarily the NASA IMAGE EUV (Inner Magnetopause to Aurora Global Experiment Extreme Ultraviolet Imager) instrument, global arrays of Global Positioning System (GPS) dual-frequency receivers, incoherent scatter radars and a suite of satellites able to measure the low-energy plasma in the inner magnetosphere) and the first two-way coupled magnetosphere-ionosphere global models. This paper will first briefly describe each of the different plumes independently (starting from the largest scale and moving to smallest scale and from the magnetosphere to the ionosphere) and then will synthesize the literature that has led to a new understanding of magnetosphere-ionosphere (MI) coupling. What is now clear is that plumes connect the equatorial $\mathrm{F}$ region ionosphere to the dayside magnetopause and the nightside magnetotail plasma sheet (e.g., Su et al., 2001a, b; Horvath and Lovell, 2011; Walsh et al., 2014a, b; Foster et al., 2014). Through the formation and evolution of the different plumes, they impact wave generation and wave-particle interactions (e.g., Summers et al., 2008; Chen et al., 2012; Halford et al., 2015), particle precipitation (Spasojević and Fuselier, 2009; Yuan et al., 2011, 2013), ion outflow (e.g., Zeng and Horowitz, 2008; Tu et al., 2007), local-time asymmetries in ULF wave field-line resonance (FLR) signatures (e.g., Archer et al., 2015; Ellington et al., 2016), satellite communication and navigation systems (Ledvina et al., 2004; Basu et al., 2005; Datta-Barua et al., 2014), and even the coupling efficiency of the solar wind to the magnetosphere (Borovsky 
and Denton, 2006; Borovsky et al., 2013; Ouellette et al., 2016; Fuselier et al., 2016). Though we now have a new appreciation and understanding of plumes, there are still many unanswered questions on their formation (e.g., Kelley et al., 2004; Horvath and Lovell, 2011; Zou et al., 2013, 2014; Borovsky et al., 2014) and impact on global magnetospheric dynamics (Borovsky et al., 1997; McFadden et al. 2008; Walsh et al., 2014, 2015). We propose that the shift in our conceptual understanding of the plasmasphere (Carpenter and Lemaire, 2004) now needs to extend down to the ionosphere and include a framework that connects the threedimensional plasmasphere-ionosphere-magnetosphere system. This short review highlights and synthesizes work performed since the launch of the IMAGE spacecraft in 2000 that has enabled the development of the validation of our understanding of the flow of dense plasma from the equatorial ionosphere into the Earth's plasma sheet.

\section{Plasmaspheric plume}

A dawn-dusk asymmetry in the shape of the plasmapause was observed in the earliest investigations of the plasmasphere (e.g., Carpenter, 1966) and was referred to as the duskside bulge (e.g., Chappell, 1974). Regions of high-density plasma were also observed beyond the plasmapause in the earliest high-inclination low-Earth orbit (e.g., Taylor et al., 1970, 1971) and equatorial elliptical and geosynchronous orbit satellite missions (e.g., Chappell, 1974; Higel and Lei, 1984; McComas et al., 1993). These were called plasmaspheric "tails" (Chappell, 1975; Maynard and Chen, 1975) or detached plasma or blobs (e.g., Chappell et al., 1970). Ober et al. (1997) were the first to call these features plumes in a paper's title. Soon after their observation, there were a number of modeling studies that suggested they were formed by dynamic sunward convection electric fields peeling away the outer layers of the plasmasphere forming the bulge and long tails towards the dayside magnetosphere (e.g., Chen and Wolf, 1972; Chen and Grewbowsky, 1978; Lemaire, 2000; Nishida, 1966).

Figure 1 shows an observation of three successive orbits of the Combined Release and Radiation Effects Satellite (CRRES) in the same local-time sector, showing the appearance of density structure beyond the main plasmapause (Moldwin et al., 2004). CRRES had a $10 \mathrm{~h}$ orbit, so significant differences in the high-density distribution are observed from one orbit to the next as well as significant outward radial motion of the innermost plasmapause location. The launch of the IMAGE EUV instrument enabled for the first time global observations of the plasmasphere and the dynamic formation and evolution of plasmaspheric plumes (e.g., Sandel et al., 2003; Goldstein, 2004; Goldstein, 2006). Figure 2 shows a sequence of IMAGE EUV-inferred plasmapause and plume locations as a function of time (Spasojević et al., 2003). The images are approximately an hour apart and show the west-

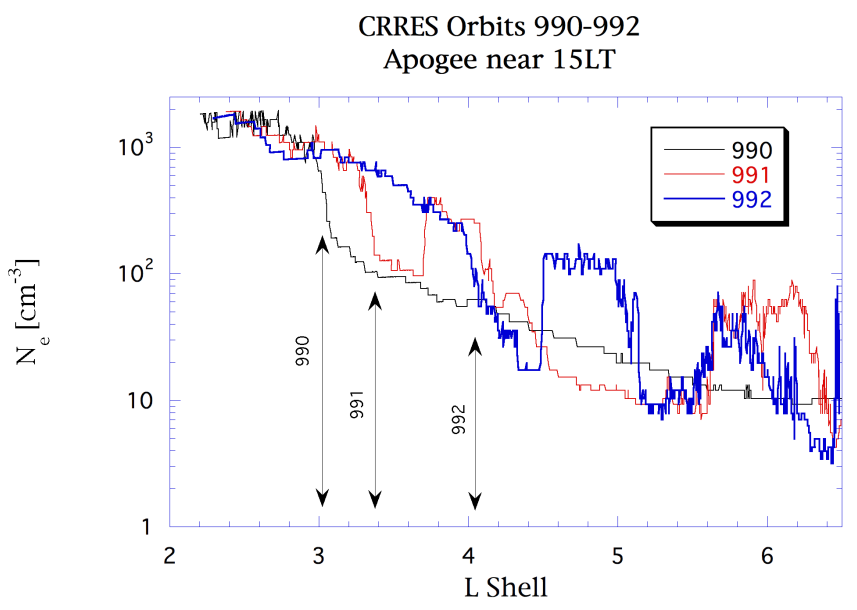

Figure 1. CRRES plasma-wave-inferred plasma density profiles of three successive orbit legs passing through the same local-time sector. Note the innermost plasmapause moves from $L$ of 3 to 3.4 to 4 and that dense plasma structure appears over the $30 \mathrm{~h}$ of the three orbits (from Moldwin et al., 2004).

ward edge of the bulge co-rotate towards the dusk sector, while the eastward edge of the plume stays nearly fixed in the dusk sector, resulting in a narrowing and elongation into a tail-like feature reminiscent of the initial magnetohydrodynamic (MHD) modeling done in the 1970s.

Over the years, using a wide variety of measurement techniques, the general properties and characteristics of plumes have been determined. They are often long-lived, being observed for days at geosynchronous orbit (e.g., Borovsky et al., 2014), are usually narrow in longitude and appear at all longitudes/MLT (e.g., Moldwin et al., 1994), can have significant structure (e.g., Moldwin et al., 1994, 1995; Darrouzet, et al., 2008; Sibanda et al., 2012), and can exist at any level of geomagnetic activity - though they are primarily associated with enhancements in activity (though not necessarily storms) (Moldwin et al., 2004). Figure 3 shows the occurrence of plumes observed by CRRES as a function of the Kp index compared to the distribution of $\mathrm{Kp}$ observed during the CRRES mission lifetime. The figure shows that plumes primarily occur for enhanced levels of $\mathrm{Kp}(>3)$ but can be observed at all levels of activity.

Many recent simple and sophisticated models of the innermagnetosphere plasma distribution have had success in explaining the formation, dynamics and complex structure of plasmasphere plumes (e.g., Goldstein et al., 2005b, 2014; He et al., 2013; Ridley et al., 2014; Nakano et al., 2014). These models all show plume formation though they take a variety of approaches by either modeling the ionosphereplasmasphere system or the inner magnetosphere. One example of the outcome of the modeling studies is the demonstration of the clear role of MI coupling has on the formation and evolution of plumes. Goldstein et al. (2003, 2005b) examined the role that sub-auroral polarization streams (SAPS) 
EUV Plasmapause Locations 26, 27 June 2001
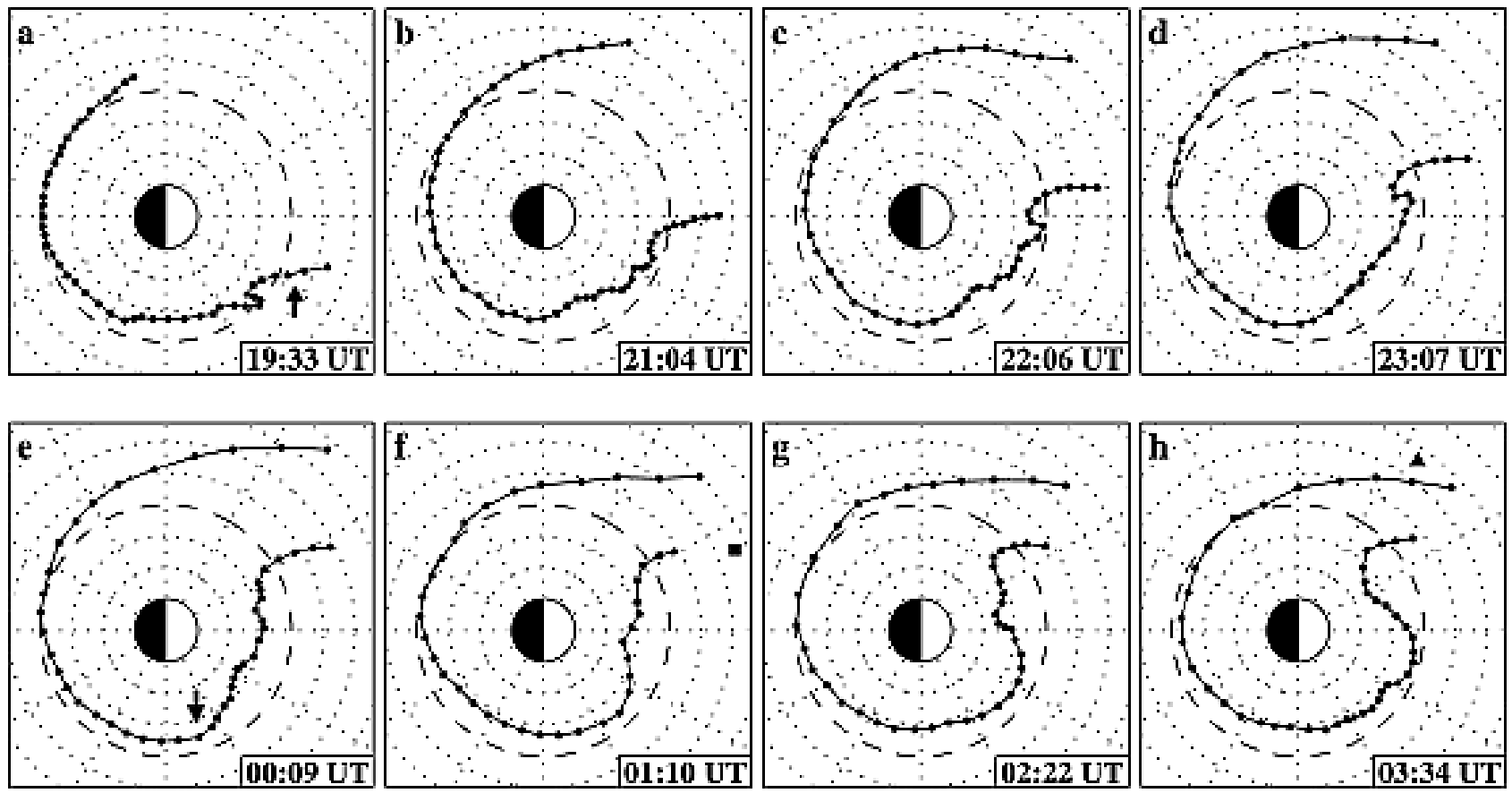

Figure 2. Plasmapause locations inferred from IMAGE EUV observations from 26-27 June 2001, showing the formation of a plasmaspheric plume and a morningside shoulder (from Spasojević et al., 2003).

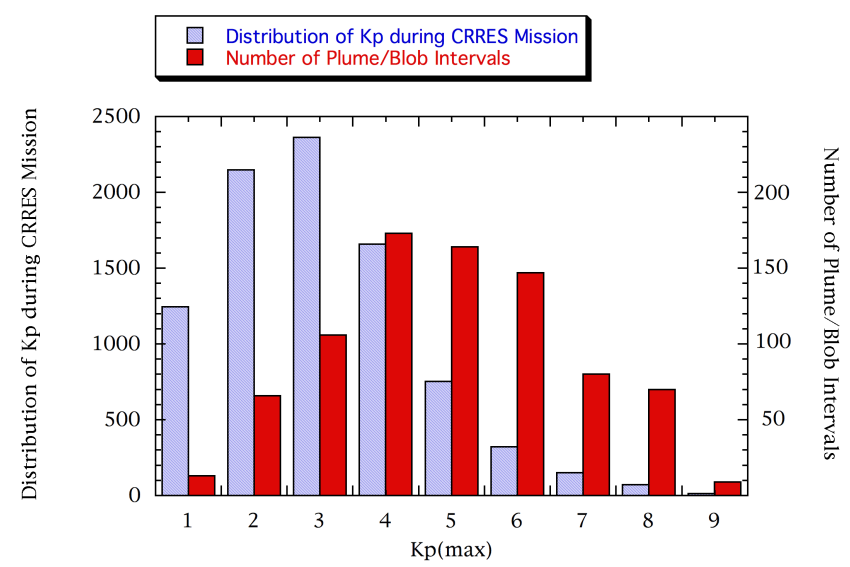

Figure 3. The distribution of Kp during the entire CRRES mission (blue bars) and for intervals when CRRES observed plasmaspheric plumes beyond the innermost plasmapause (from Moldwin et al., 2004).

have on plume formation and structure. SAPS are regions in which large ionospheric electric fields are observed and are due to region 2 field-aligned current (FAC) through the lowconductivity midlatitude trough region (e.g., Foster and Vo, 2002). Inclusion of a dusk-side SAPS feature in their model, clearly helped reproduce the observed plume structure better than the inclusion of only simple global convection electric fields.

\section{SED plume}

An increase in ionospheric density in the aftermath of geomagnetic disturbances at midlatitudes has been long observed (see review by Mendillo, 2007). The earliest studies identified the recurrent feature of a "positive phase" (density enhancement) routinely in the dusk sector (and hence often called the positive-phase dusk effect and more recently storm-enhanced density (SED)). This was initially observed in single-station ionosondes, then radio beacons, then ISR (e.g., Foster, 1993), then GPS networks (e.g., Coster and Skone, 2009) and then sophisticated data assimilation models combining many different datasets (e.g., Garner et al., 2005). As multipoint measurements became more common (e.g., Su et al., 2001b), the name plumes began to appear, and with the seminal work of Foster et al. (2002) connecting the ionospheric SED signature with the plasmaspheric plume feature, the term SED plume began to appear regularly (e.g., Yizengaw et al., 2006; Foster, 2008). These SED plumes are observed in all MLT sectors but are preferentially observed in the American sector due to the tilt of the dipole geomagnetic field (e.g., Foster et al., 2008; Yizengaw et al., 2006; Coster et al., 2007; Thomas et al., 2016). The largest values of TEC are also observed in the American sector (Coster et al., 2007). Like plasmaspheric plumes, SED ionospheric plumes are associated with geomagnetic storms and enhanced geomagnetic activity. 

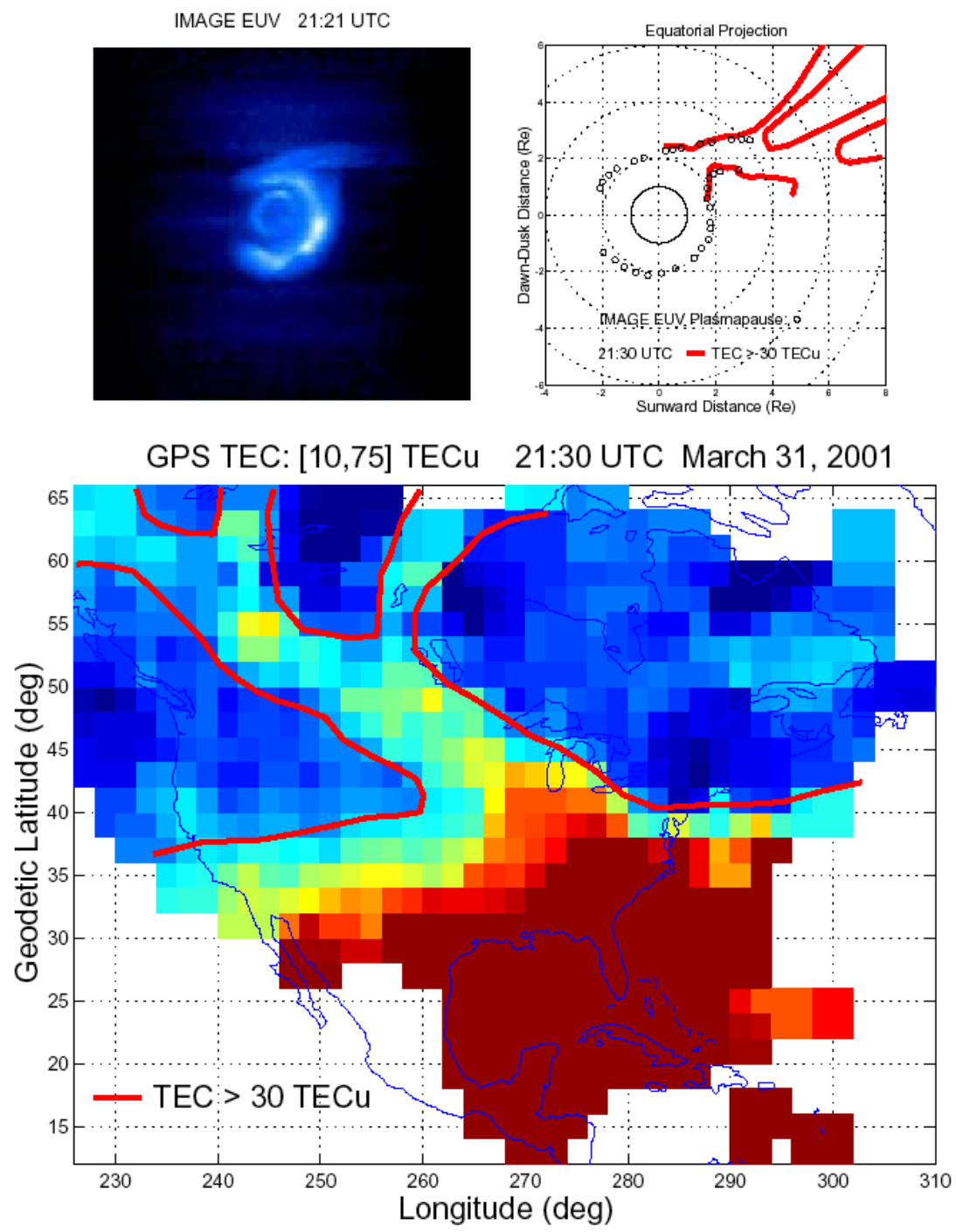

Figure 4. An IMAGE EUV plasmasphere image and the coincident GPS TEC map over North America showing that the boundary of the SED plume (red lines) matches the boundary of the location of the plasmaspheric plume (from Foster et al., 2002).

Figure 4 shows the observational evidence showing that plasmaspheric plumes and SED plumes are the ionospheric and magnetospheric manifestations of the flow of low-L/lowlatitude high-density plasma to higher-L/latitudes and was obtained by combining IMAGE EUV observations of the plasmaspheric plume with TEC observations of the ionospheric SED plume (Foster et al., 2002). This paper unambiguously connected SED ionospheric plumes with plasmaspheric plumes and showed that a new three-dimensional topside ionosphere-plasmasphere-magnetosphere flux tube conceptual framework is needed to understand plasma redistribution within the MI system.

Further evidence connecting the two features was also presented by combining the IMAGE EUV observation of the plume with the in situ density observation taken during the subsequent fly-through of the plume at a lower al- titude (e.g., Garcia et al., 2003). Figure 5 shows a schematic of the field-aligned flux tube high-density regions mapping to the equatorial plane picture of the plasmaspheric plume taken by IMAGE EUV. The high-density regions labeled A and $\mathrm{B}$ are also indicated in the Radio Plasma Imager (RPI) plasma wave spectrogram inset. In addition, Yizengaw and Moldwin (2005) combined tomographic reconstructions of ionospheric density profiles with the mapped location of the plasmapause as determined by IMAGE EUV and showed that the ionospheric midlatitude trough at $\mathrm{F}$ region and topside ionosphere altitudes is collocated with the plasmapause (Fig. 6). Numerous subsequent observations of in situ plasmaspheric plume density associated with ionospheric SED plume enhancements have been made by satellites in lowEarth orbit (e.g., Lin et al., 2007) and the Van Allen probes (e.g., Foster et al., 2014). These studies found that the iono- 


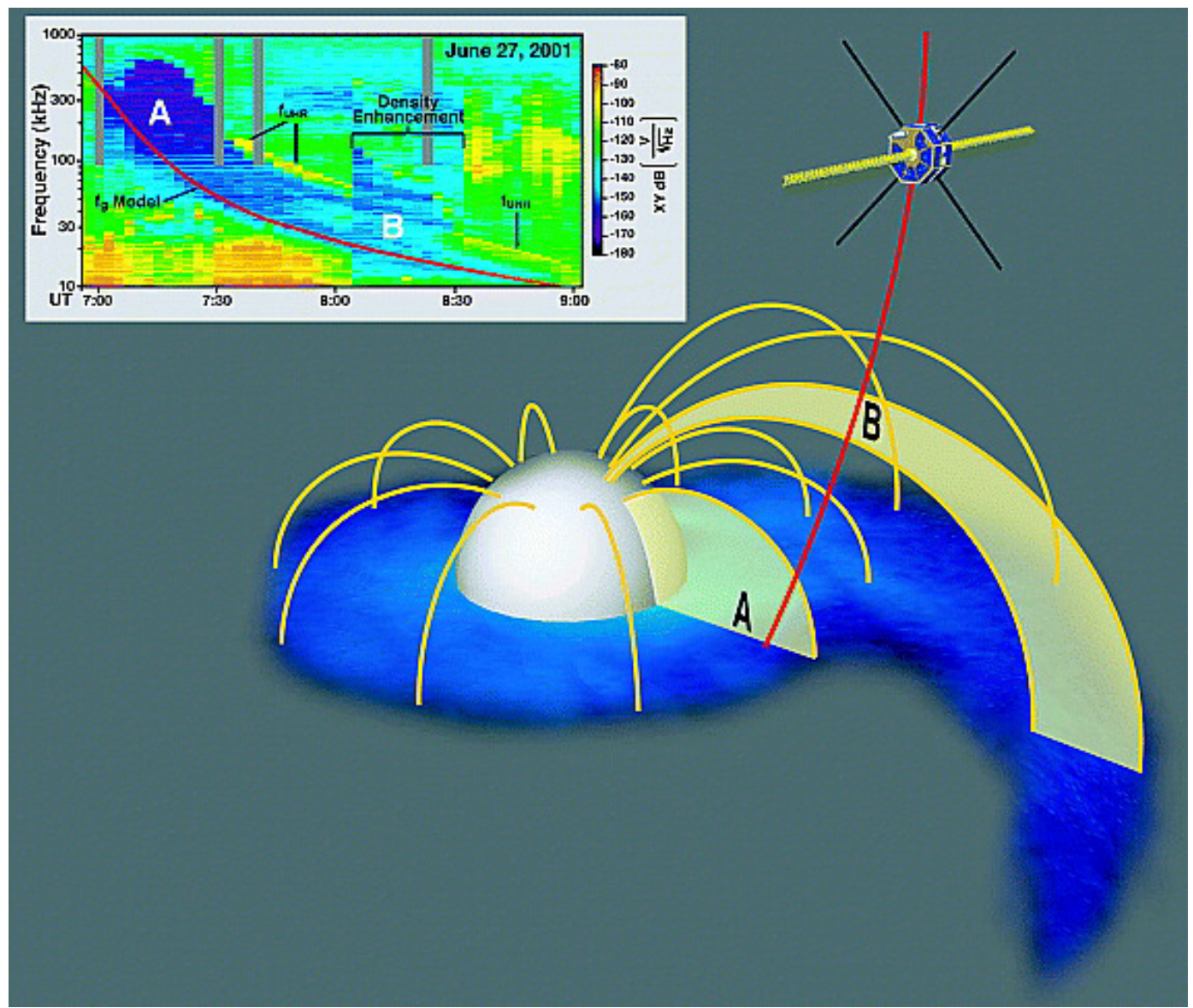

Figure 5. A schematic of the flux tube mapping of the IMAGE EUV plasmasphere (a) and the plasmaspheric plume (b) overlaid on the IMAGE EUV image projected onto the equatorial plane. After the image was taken, the IMAGE RPI instrument sampled this region during its inbound orbit pass and observed the density structure shown in the inset. Note that there is a clear plume (b) at higher $L$ than the main plasmasphere (a) (from Garcia et al., 2003).

spheric and plasmaspheric plumes have similar behavior in their density variability and location of the steep density gradients indicating that the SED ionospheric plumes maps into the ionosphere. Coster et al. (2003) and Yuan et al. (2009) determined the vertical altitude density profile within a SED plume and found that about half of the total TEC is above $800 \mathrm{~km}$ (Fig. 7), showing that SED plumes contain redistributed plasma (not just enhanced $\mathrm{F}$ region peak densities) and are clearly connected to the dense plasmaspheric plasma in the magnetosphere. The topside "heavy" distribution of the SED plume shows that the plasma is due to the redistribution of uplifted $\mathrm{F}$ region plasma and also downflowing plasmaspheric plasma (e.g., Bailey and Sellek, 1992). A modeling study showed the complex interplay of plasma flows in the generation of super-fountain effect equatorial dynamics (Lu et al., 2013) that can create enhanced and higherlatitude equatorial anomaly features that can connect to SED features. Recent studies by Zou et al. $(2013,2014)$ using multiple instruments, in particular the Poker Flat incoherent scatter radar (PFISR), as well as Zou and Ridley (2016), using the Global Ionosphere-Thermosphere Model (GITM), highlighted the importance of the interplay among the convection flows, thermospheric winds and ambipolar diffusion within the SED plume in determining the density structures within the plume and the fate of the plume. Downward plasma flows within the plumes were reported on the dayside ionosphere due to a combination of enhanced poleward thermospheric winds and enhanced ambipolar diffusion (Zou et al., 2014, 2016).

As the SED density convects poleward towards the cusp (in the ionosphere) and sunward towards the dayside magnetopause (in the magnetosphere), a plume of high density is observed in the polar cap ionosphere (e.g., Steele and Cogger, 1996; Foster et al., 2005) and at high altitudes on open field lines over the polar cap (e.g., Tu et al., 2007). This socalled tongue of ionization (TOI) connects the plume with cusp ion outflow (e.g., Zeng and Horowitz, 2008; Walsh et al., 2014b) and dense ionospheric density contributions to the plasma sheet (e.g., Elphic et al., 1997; Borovsky et al., 1997). 


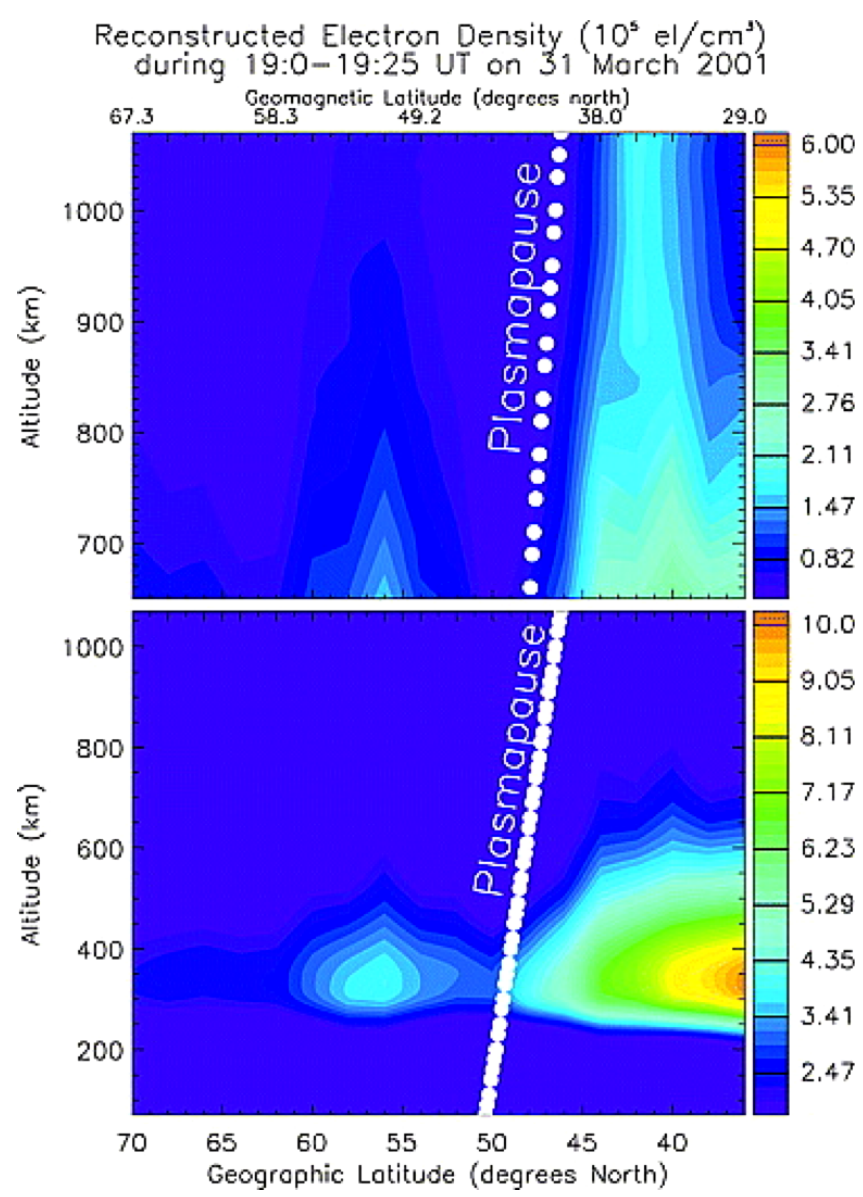

Figure 6. The GPS TEC tomographic reconstruction of a meridional cross section of the midlatitude to polar cap ionosphere showing the main $\mathrm{F}$ region ionosphere, midlatitude trough region and auroral precipitation-enhanced densities. The dotted line labeled plasmapause was extracted from the concurrent plasmapause location from IMAGE EUV. The top panel shows the topside ionosphere-plasmasphere transition height (with different color bar) (from Yizengaw and Moldwin, 2005).

There has been considerable modeling of the ionospheric SED plume (e.g., Lin et al., 2005) and of the plasmaspheric plume (e.g., Huba and Krall, 2013), but recently the first self-consistent model of the ionosphere and magnetosphere electric field drivers has been done with the SAMI3-RCM simulation of the 31 March 2001 geomagnetic storm (Huba and Sazykin, 2014). Figure 8 shows the projection of electron density in the equatorial plane and a synthetic global TEC map showing how the plasmaspheric plume maps to the ionospheric SED plume. The model used inner-magnetospheric electric fields from the Rice Convection Model (RCM) to drive the SAMI3 (another model of the ionosphere) ionosphere-plasmasphere system selfconsistently and found that the penetration electric fields created the SED at low and midlatitudes and this ionospheric

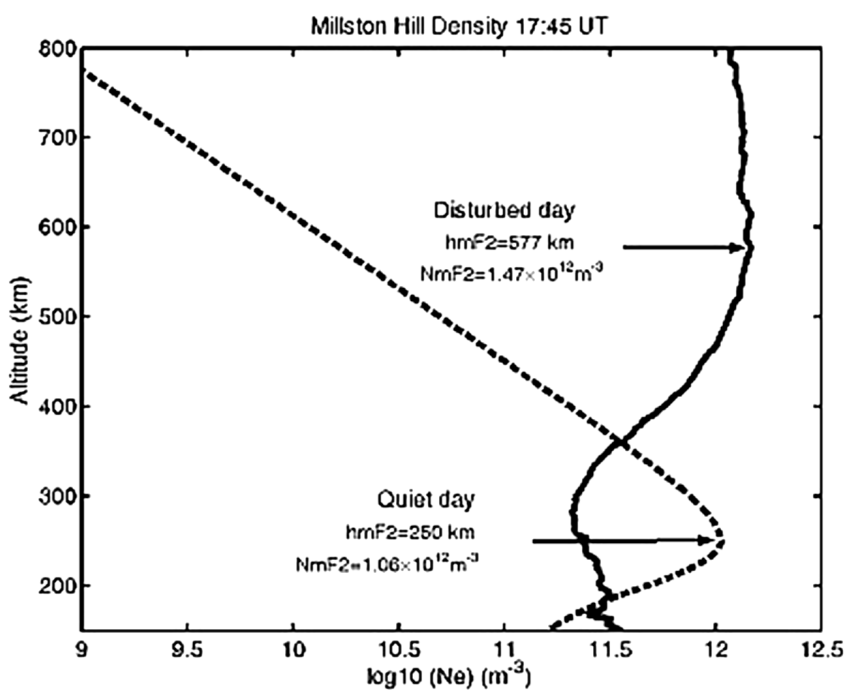

Figure 7. A vertical density profile in a SED plume at 17:45 UT (solid line) observed with the Millstone Hill incoherent scatter radar on 20 November 2003 compared with a quiet-time reference profile taken on 19 November 2003 (dashed line). Note that the topside ionosphere is greatly enhanced (from Yuan et al., 2009).

structure mapped to the plasmaspheric plume in the equatorial magnetosphere.

\section{Equatorial plasma plumes}

The equatorial ionosphere is often considered disconnected from the rest of the magnetosphere since the geomagnetic field threads the ionosphere horizontally. However, it has been well known that storm time electric fields can penetrate to the equatorial region, enhancing the equatorial electrojet driving a vertical uplift of the plasma and through the fountain effect creating the equatorial anomalies (e.g., Abdu, 1997; Tsurutani et al., 2004) (Fig. 9). The term anomaly was given to these regions as it was originally expected that the peak ionospheric density should be at the subsolar point, but instead it was observed that there was a minima at the equator and two peaks of enhanced density at about $\pm 15^{\circ}$ off the geomagnetic equator (Appleton, 1946). The equatorial anomalies are regions of enhanced ionospheric density that are often observed in the dayside through the dusk sector and are modulated by geomagnetic activity and neutral winds (e.g., Abdu et al., 1991). The anomalies arise due to an $\boldsymbol{E} \times \boldsymbol{B}$ uplift of the $\mathrm{F}$ region plasma due to an equatorial horizontal electric field. The lifted plasma then settles gravitationally along the magnetic field at higher latitudes. In addition, the uplift of the equatorial ionosphere due to enhanced $\boldsymbol{E}$ fields at dusk often sets off plasma instabilities (e.g., Basu et al., 1980; Kelley et al., 2011) that gives rise to low-density bubbles or plumes. Note that in this context the terms bubble and plumes are used to describe low-density regions and the 


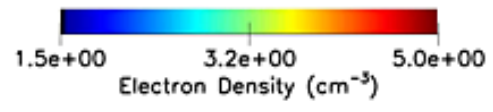

DAY 090 UT 08:00
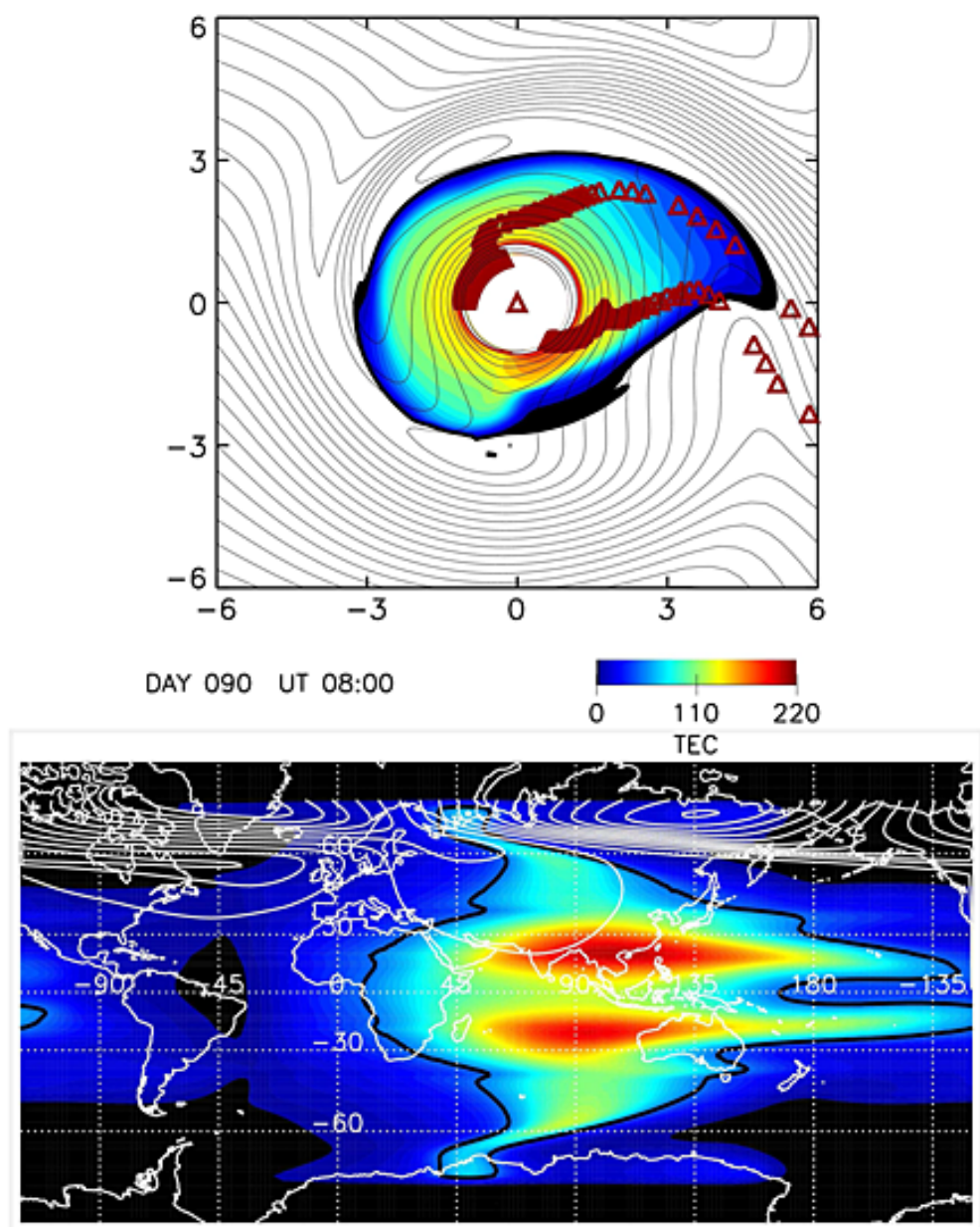

Figure 8. The storm time (top) plasmasphere showing color contours of density and black line contours of electric potential. The red triangles show where the TEC $=50 \mathrm{TECU}$ maps to the equatorial plane. The (bottom panel) ionosphere shows color contours of the TEC, and the black contour line is where TEC $=50$ TECU (from Huba and Sazykin, 2014).

plasma motion associated with these regions (e.g., Bernhardt, 2007; Krall et al., 2010). Some of the small-scale density structures have been suggested to be convected to midlatitudes in the SED plumes, giving rise to midlatitude irregularity as well (e.g., Horvath and Lovell, 2011).

During large storms, the $\mathrm{F}$ region ionosphere can be lifted to very high altitudes, giving rise to the so-called superfountain effect (e.g., Lu et al., 2013) and extreme values of TEC at midlatitudes by moving the equatorial anomaly further poleward (e.g., Mannucci et al., 2005). During superstorms, this redistribution of dense equatorial plasma to midlatitudes (and from the inner plasmasphere to the outer plasmasphere) enables this plasma to be caught up in the sunward convection flow forming the midlatitude SED and plasmaspheric plume. The common sunward convection trajectories of these two dense plasma regions further demonstrate their connection (e.g., Foster et al., 2007). The mapping of ionospheric SAPS electric fields to the outer edge of the plasmaspheric plume also demonstrate the connection (e.g., Foster et al., 2007; Goldstein et al., 2005b; Lin et al., 2007). Since the equatorial dense plasma reaches the midlatitudes through the fountain effect, it is distributed along the flux tube at a higher altitude than the "normal" $\mathrm{F}$ region peak, giving rise to the heavy topside density distribution. The enhanced density in the plasmaspheric plumes and SEDs continue to $\boldsymbol{E} \times \boldsymbol{B}$ drift sunward impacting the dayside magnetopause (e.g., Walsh et al., 2014) and forming the so-called TOI over the polar cap (e.g., Thomas et al., 2013). 


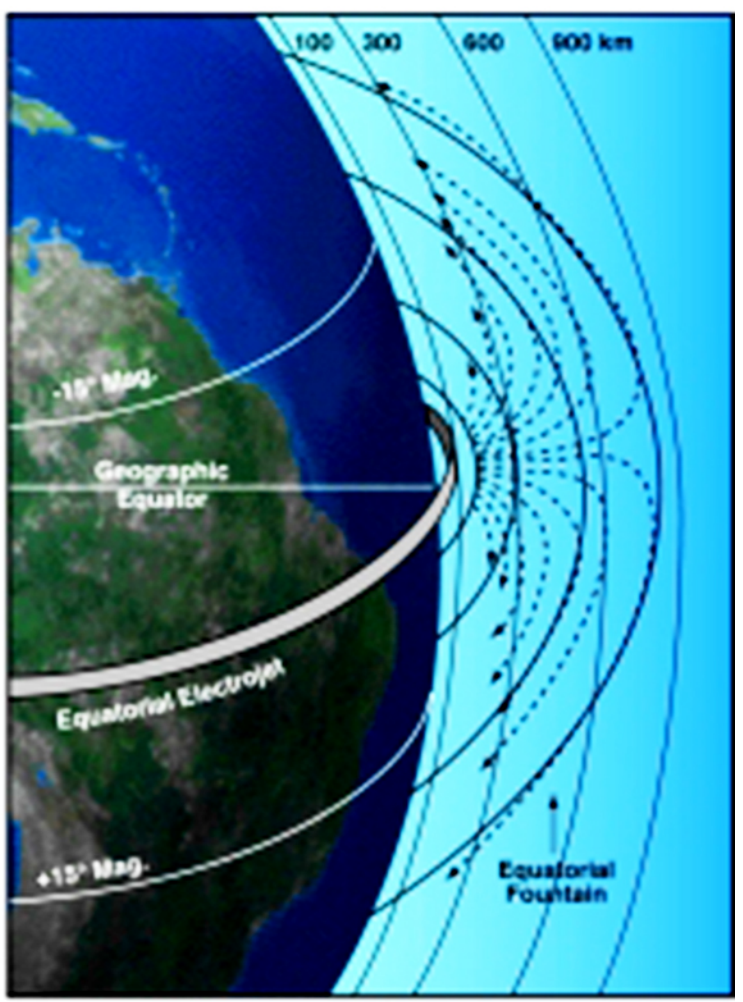

Figure 9. The equatorial ionosphere showing the flow pattern associated with the fountain effect of moving low-altitude equatorial plasma to a higher altitude (from Blitza, 2016).

\section{Conclusions}

The story of the plume family developed over the last 15 years or so is the story of more fully understanding magnetosphere-ionosphere coupling. We now have evidence (both observational and modeling) to show that there is a redistribution of plasma from the equatorial ionosphere into the outer plasmasphere that participates in inner-magnetospheric convection to the dayside magnetopause and cusp region. This cold, dense plasma modulates dayside reconnection, plasma and ULF wave generation and propagation, and truly connects the topside ionosphere and magnetosphere through ion outflow, contributing to the mass density of the magnetotail plasma sheet. As reviewed above, a significant number of studies published over the last 15 years demonstrate that plumes tell us that there is strong two-way coupling between the magnetosphere and ionosphere during geomagnetic activity - not only does the ionosphere respond to magnetospheric forcing during storms, but through its impact on wave generation, wave-particle interactions, ion outflow and mass loading at the dayside magnetopause and in the magnetotail, dense plasma plumes modulate the subsequent magnetospheric dynamics.

\section{Data availability}

No original data are described in this review paper. All data presented have been published previously.

Acknowledgements. This work was partially support by NSF AGS 1450512. Shasha Zou would like to acknowledge NSF AGS1342968 and NASA NNX14AF31G. The lead author thanks the organizing committee of the International Symposium of Equatorial Aeronomy 14 Workshop held in Bahir Dar Ethiopia for the invitation to present a talk. This paper is based on that presentation. The authors thank the editor and the two referees for suggestions that significantly improved the presentation.

The topical editor, P. J. Erickson, thanks J. Foster, D. Gallagher, and one anonymous referee for help in evaluating this paper.

\section{References}

Abdu, M. A.: The Ninth International Symposium on Equatorial Aeronomy, Major phenomena of the equatorial ionospherethermosphere system under disturbed conditions, J. Atmos. Sol.Terr. Phy., 59, 1505-1519, 1997.

Abdu, M. A., Sobral, J. H. A., de Paula, E. R., and Batista, I. S.: Magnetospheric disturbance effects on the Equatorial Ionization Anomaly (EIA): an overview, J. Atmos. Terr. Phys., 53, 757-771, 1991.

Appleton, E. V.: Two Anomalies in the Ionosphere, Nature, 157, 691 pp., doi:10.1038/157691a0, 1964.

Archer, M. O., Hartinger, M. D., Walsh, B. M., Plaschke, F., and Angelopoulos, V.: Frequency variability of standing Alfvén waves excited by fast mode resonances in the outer magnetosphere, Geophys. Res. Lett., 42, 10150-10159, 2015.

Bailey, G. J. and Sellek, R.: Field-aligned flows of $\mathrm{H}^{+}$and $\mathrm{He}^{+}$ in the mid-latitude topside ionosphere at solar maximum, Planet. Space Sci., 40, 751-762, 1992.

Basu, S., McClure, J., Basu, S., Hanson, W., and Aarons, J.: Coordinated study of equatorial scintillation and in situ and radar observations of nighttime $F$ region irregularities, J. Geophys. Res., 85, 5119-5130, 1980.

Basu, S., Makela, J. J., Sheehan, R. E., MacKenzie, E., Doherty, P., Wright, J. W., Keskinen, M. J., Pallamraju, D., Paxton, L. J., and Berkey, F. T.: Two components of ionospheric plasma structuring at midlatitudes observed during the large magnetic storm of 30 October 2003, Geophys. Res. Lett., 32, L12S06, doi:10.1029/2004GL021669, 2005.

Bernhardt, P. A.: Quasi-analytic models for density bubbles and plasma clouds in the equatorial ionosphere: 2. A simple Lagrangian transport model, J. Geophys. Res., 112, A11310, doi:10.1029/2007JA012287, 2007.

Bilitza, D.: International Reference Ionosphere, http://iri.gsfc.nasa. gov/, last access: 24 August 2016.

Borovsky, J. E. and Denton, M. H.: Effect of plasmaspheric drainage plumes on solar-wind/magnetosphere coupling, Geophys. Res. Lett., 33, L20101, doi:10.1029/2006GL026519, 2006.

Borovsky, J. E., Thomsen, M. F., and McComas, D. J.: The superdense plasma sheet: Plasmaspheric origin, solar wind origin, or ionospheric origin?, J. Geophys. Res., 102, 22089-22097, doi:10.1029/96JA02469, 1997. 
Borovsky, J. E., Denton, M. H., Denton, R. E., Jordanova, V. K., and Krall, J.: Estimating the effects of ionospheric plasma on solar wind/magnetosphere coupling via mass loading of dayside reconnection: Ion-plasma-sheet oxygen, plasmaspheric drainage plumes, and the plasma cloak, J. Geophys. Res. Space Phys., 118, 5695-5719, doi:10.1002/jgra.50527, 2013.

Borovsky, J. E., Welling, D. T., Thomsen, M. F., and Denton, M. H.: Long-lived plasmaspheric drainage plumes: Where does the plasma come from?, J. Geophys. Res. Space Phys., 119, 64966520, doi:10.1002/2014JA020228, 2014.

Carpenter, D. L.: Whistler studies of the plasmapause in the magnetosphere: 1 . Temporal variations in the position of the knee and some evidence on plasma motions near the knee, J. Geophys. Res., 71, 693-709, doi:10.1029/JZ071i003p00693, 1966.

Carpenter, D. L. and Lemaire, J.: The Plasmasphere Boundary Layer, Ann. Geophys., 22, 4291-4298, doi:10.5194/angeo-224291-2004, 2004.

Chappell, C. R.: Detached plasma regions in the magnetosphere, J. Geophys. Res., 79, 1861-1870, 1974.

Chappell, C. R.: Ionosphere-magnetosphere coupling: 1. Thermal plasma, Rev. Geophys., 13, 872-873, doi:10.1029/RG013i003p00872, 1975.

Chappell, C. R., Harris, K. K., and Sharp, G. W.: The morphology of the bulge region of the plasmasphere, J. Geophys. Res., 75, 3848-3861, doi:10.1029/JA075i019p03848, 1970.

Chen, A. J. and Wolf, R. A.: Effects on the plasmasphere of a timevarying convection electric field, Planet. Space Sci., 20, 483$509,1972$.

Chen, A. J. and Grebowsky, J. M.: Dynamical interpretation of observed plasmasphere deformations, Planet. Space Sci., 26, 661672,1978

Chen, L., Thorne, R. M., Li, W., Bortnik, J., Turner, D., and Angelopoulos, V.: Modulation of plasmaspheric hiss intensity by thermal plasma density structure, Geophys. Res. Lett., 39, L14103, doi:10.1029/2012GL052308, 2012.

Coster, A. and Skone, S.: Monitoring storm-enhanced density using IGS reference station data, S. J. Geod., 83, 345-351, doi:10.1007/s00190-008-0272-3, 2009.

Coster, A. J., Foster, J. C., and Erickson, P. J.: Monitoring the Ionosphere with GPS, GPS World, May, 42-49, 2003.

Coster, A. J., Colerico, M. J., Foster, J. C., Rideout, W., and Rich, F.: Longitude sector comparisons of storm enhanced density, Geophys. Res. Lett., 34, L18105, doi:10.1029/2007GL030682, 2007.

Darrouzet, F., Gallagher, D. L., André, N., Carpenter, D. L., Dandouras, I., Décréau, P. M. E., De Keyser, J., Denton, R. E., Foster, J. C., Goldstein, J., Moldwin, M. B., Reinisch, B. W., Sandel, B. R., and Tu, J.: Plasmaspheric density structures and dynamics: Properties observed by the CLUSTER and IMAGE missions, Space Sci. Rev., 145, 55-106, doi:10.1007/s11214-008-9438-9, 2008.

Datta-Barua, S., Walter, T., Bust, G. S., and Wanner, W.: Effects of solar cycle 24 activity on WAAS navigation, Space Weather, 12, 46-63, doi:10.1002/2013SW000982, 2014.

Ellington, S. M., Moldwin, M. B., and Liemohn, M. W.: Local time asymmetries and toroidal field line resonances: Global magnetospheric modeling in SWMF, J. Geophys. Res. Space Phys., 121, 2033-2045, doi:10.1002/2015JA021920, 2016.
Elphic, R. C., Thomsen, M. F., and Borovsky, J. E.: Fate of the Outer Plasmasphere, Geophys. Res. Lett., 24, 365-368, doi:10.1029/97GL00141, 1997.

Foster, J. C.: Storm time plasma transport at middle and high latitudes, J. Geophys. Res., 98, 1675-1689, doi:10.1029/92JA02032, 1993.

Foster, J. C.: Ionospheric-magnetospheric-heliospheric coupling: Storm-time thermal plasma redistribution, Midlatitude Ionospheric Dynamics and Disturbances, edited by: Kintner Jr, P. M., Coster, A. J., Fuller-Rowell, T., Mannucci, A. J., Mendillo, M., and Heelis, R., AGU, Washington, DC, Geophys. Monogr. Ser. 181, 121-134, 2008.

Foster, J. C. and Vo, H. B.: Average characteristics and activity dependence of the subauroral polarization stream, J. Geophys. Res., 107, 1475, doi:10.1029/2002JA009409, 2002.

Foster, J. C., Erickson, P. J., Coster, A. J., Goldstein, J., and Rich, F. J.: Ionospheric signatures of plasmaspheric tails, Geophys. Res. Lett., 29, 1623, doi:10.1029/2002GL015067, 2002.

Foster, J. C., Coster, A. J., Erickson, P. J., Holt, J. M., Lind, F. D., Rideout, W., McCready, M., van Eyken, A., Barnes, R. J., Greenwald, R. A., and Rich, F. J.: Multiradar observations of the polar tongue of ionization, J. Geophys. Res., 110, A09S31, doi:10.1029/2004JA010928, 2005.

Foster, J. C., Rideout, W., Sandel, B., Forrester, W. T., and Rich, F. J.: On the relationship of SAPS to storm-enhanced density, J. Atmos. Sol.-Terr. Phy., 69, 303-313, 2007.

Foster, J. C., Erickson, P. J., Coster, A. J., Thaller, S., Tao, J., Wygant, J. R., and Bonnell, J. W.: Storm time observations of plasmasphere erosion flux in the magnetosphere and ionosphere, Geophys. Res. Lett., 41, 762-768, doi:10.1002/2013GL059124, 2014.

Fuselier, S. A., Burch, J. L., Cassak, P. A., Goldstein, J., Gomez, R. G., Goodrich, K., Lewis, W. S., Malaspina, D., Mukherjee, J., Nakamura, R., Petrinec, S. M., Russell, C. T., Strangeway, R. J., Torbert, R. B., Trattner, K. J., and Valek, P.: Magnetospheric ion influence on magnetic reconnection at the duskside magnetopause, Geophys. Res. Lett., 43, 1435-1442, doi:10.1002/2015GL067358, 2016.

Garcia, L. N., Fung, S. F., Green, J. L., Boardsen, S. A., Sandel, B. R., and Reinisch, B. W.: Observations of the latitudinal structure of plasmaspheric convection plumes by IMAGE-RPI and EUV, J. Geophys. Res., 108, 1321, doi:10.1029/2002JA009496, 2003.

Garner, T. W., Bust, G. S., Gaussiran II, T. L., and Straus, P. R.: Variations in the midlatitude and equatorial ionosphere during the October 2003 magnetic storm, Radio Sci., 41, RS6S08, doi:10.1029/2005RS003399, 2006.

Goldstein, J.: Simultaneous remote sensing and in situ observations of plasmaspheric drainage plumes, J. Geophys. Res., 109, A03202, doi:10.1029/2003JA010281, 2004

Goldstein, J.: Plasmasphere Response: Tutorial and Review of Recent Imaging Results, Space Sci. Rev., 124, 203-216, 2006.

Goldstein, J., Sandel, B. R., Hairston, M. R., and Reiff, P. H.: Control of plasmaspheric dynamics by both convection and sub-auroral polarization stream, Geophys. Res. Lett., 30, 2243, doi:10.1029/2003GL018390, 2003.

Goldstein, J., Burch, J. L., and Sandel, B. R.: Magnetospheric model of subauroral polarization stream, J. Geophys. Res., 110, A09222, doi:10.1029/2005JA011135, 2005a. 
Goldstein, J., Sandel, B. R., Forrester, W. T., Thomsen, M. F., and Hairston, M. R.: Global plasmasphere evolution 22-23 April 2001, J. Geophys. Res., 110, A12218, doi:10.1029/2005JA011282, 2005b.

Goldstein, J., Thomsen, M. F., and DeJong, A.: In situ signatures of residual plasmaspheric plumes: Observations and simulation, J. Geophys. Res. Space Phys., 119, 4706-4722, doi:10.1002/2014JA019953, 2014.

Halford, A. J., Fraser, B. J., and Morley, S. K.: EMIC waves and plasmaspheric and plume density: CRRES results, J. Geophys. Res. Space Phys., 120, 1974-1992, doi:10.1002/2014JA020338, 2015.

He, F., Zhang, X.-X., Chen, B., Fok, M.-C., and Zou, Y.-L.: Moon-based EUV imaging of the Earth's Plasmasphere: Model simulations, J. Geophys. Res. Space Phys., 118, 7085-7103, doi:10.1002/2013JA018962, 2013.

Higel, B. and Lei, W.: Electron density and plasmapause characteristics at $6.6 R_{\mathrm{E}}$ : A statistical study of the GEOS 2 relaxation sounder data, J. Geophys. Res., 89, 1583-1601, doi:10.1029/JA089iA03p01583, 1984.

Horvath, I. and Lovell, B. C.: Storm-enhanced plasma density (SED) features, auroral and polar plasma enhancements, and rising topside bubbles of the 31 March 2001 superstorm, J. Geophys. Res., 116, A04307, doi:10.1029/2010JA015514, 2011

Huba, J. and Krall, J.: Modeling the plasmasphere with SAMI3, Geophys. Res. Lett., 40, 6-10, doi:10.1029/2012GL054300, 2013.

Huba, J. D. and Sazykin, S.: Storm time ionosphere and plasmasphere structuring: SAMI3-RCM simulation of the 31 March 2001 geomagnetic storm, Geophys. Res. Lett., 41, 8208-8214, doi:10.1002/2014GL062110, 2014.

Kelley, M. C., Vlasov, M. N., Foster, J. C., and Coster, A. J.: A quantitative explanation for the phenomenon known as storm-enhanced density, Geophys. Res. Lett., 31, L19809, doi:10.1029/2004GL020875, 2004.

Kelley, M. C., Makela, J. J., de La Beaujardière, O., and Retterer, J.: Convective ionospheric storms: A review, Rev. Geophys., 49, RG2003, doi:10.1029/2010RG000340, 2011.

Krall, J., Huba, J. D., Ossakow, S. L., and Joyce, G.: Equatorial spread $F$ fossil plumes, Ann. Geophys., 28, 2059-2069, doi:10.5194/angeo-28-2059-2010, 2010.

Ledvina, B. M., Kintner, P. M., and Makela, J. J.: Temporal properties of intense GPS L1 amplitude scintillations at midlatitudes, Radio Sci., 39, RS1S18, doi:10.1029/2002RS002832, 2004.

Lemaire, J. F.: The formation plasmaspheric plumes, Phys. Chem. Earth, 25, 9-17, 2000.

Lin, C. H., Richmond, A. D., Heelis, R. A., Bailey, G. J., Lu, G., Liu, J. Y., Yeh, H. C., and Su, S.-Y.: Theoretical study of the low- and midlatitude ionospheric electron density enhancement during the October 2003 superstorm: Relative importance of the neutral wind and the electric field, J. Geophys. Res., 110, A12312, doi:10.1029/2005JA011304, 2005.

Lin, C. S., Yeh, H.-C., Sandel, B. R., Goldstein, J., Rich, F. J., Burke, W. J., and Foster, J. C.: Magnetospheric Convection near a Drainage Plume, J. Geophys. Res., 112, A05216, doi:10.1029/2006JA011819, 2007.

Lu, G., Huba, J. D., and Valladares, C.: Modeling ionospheric super-fountain effect based on the coupled TIMEGCM-
SAMI3, J. Geophys. Res. Space Phys., 118, 2527-2535, doi:10.1002/jgra.50256, 2013.

Mannucci, A. J., Tsurutani, B. T., Iijima, B., Komjathy, A., Wilson, B., Pi, X., Sparks, L., Hajj, G., Mandrake, L., Gonzalez, W. D., Kozyra, J., Yumoto, K., Swisdak, M., Huba, J. D., and Skoug, R.: Hemispheric Daytime Ionospheric Response to Intense Solar Wind Forcing, in: Inner Magnetosphere Interactions: New Perspectives from Imaging, edited by: Burch, J., Schulz, M., and Spence, H., American Geophysical Union, Washington, DC, doi:10.1029/159GM20, 2005.

Maynard, N. C. and Chen, A. J.: Isolated cold plasma regions: Observations and their relation to possible production mechanisms, J. Geophys. Res., 80, 1009-1013, doi:10.1029/JA080i007p01009, 1975.

McComas, D. J., Bame, S. J., Barraclough, B. L., Donart, J. R., Elphic, R. C., Gosling, J. T., Moldwin, M. B., Moore, K. R., and Thomsen, M. F.: Magnetospheric plasma analyzer: Initial threespacecraft observations from geosynchronous orbit, J. Geophys. Res., 98, 13453-13465, doi:10.1029/93JA00726, 1993.

McFadden, J. P., Carlson, C. W., Larson, D., Bonnell, J., Mozer, F. S., Angelopoulos, V., Glassmeier, K.-H., and Auster, U.: Structure of plasmaspheric plumes and their participation in magnetopause reconnection: First results from THEMIS, Geophys. Res. Lett., 35, L17S10, doi:10.1029/2008GL033677, 2008.

Mendillo, M.: Storms in the ionosphere: Patterns and processes for total electron content, Rev. Geophys., 44, RG4001, doi:10.1029/2005RG000193, 2006.

Moldwin, M. B., Thomsen, M. F., Bame, S. J., McComas, D. J., and Moore, K. R.: An examination of the structure and dynamics of the outer plasmasphere using multiple geosynchronous satellites, J. Geophys. Res., 99, 1475-11481, 1994.

Moldwin, M. B., Thomsen, M. F., Bame, S. J., McComas, D., and Reeves, G. D.: The fine-scale structure of the outer plasmasphere, J. Geophys. Res., 100, 8021-8029, doi:10.1029/94JA03342, 1995.

Moldwin, M. B., Howard, J., Sanny, J., Bocchicchio, J. D., Rassoul, H. K., and Anderson, R. R.: Plasmaspheric plumes: CRRES observations of enhanced density beyond the plasmapause, J. Geophys. Res., 109, A05202, doi:10.1029/2003JA010320, 2004.

Nakano, S., Fok, M.-C., Brandt, P. C., and Higuchi, T.: Estimation of temporal evolution of the helium plasmasphere based on a sequence of IMAGE/EUV images, J. Geophys. Res. Space Phys., 119, 3708-3723, doi:10.1002/2013JA019734, 2014.

Nishida, A.: Formation of plasmapause, or magnetospheric plasma knee, by the combined action of magnetospheric convection and plasma escape from the tail, J. Geophys. Res., 71, 5669-5679, 1966.

Ober, D. M., Horwitz, J. L., Thomsen, M. F., Elphic, R. C., McComas, D. J., Belian, R. D., and Moldwin, M. B.: Premidnight plasmaspheric "plumes", J. Geophys. Res., 102, 11325-11334, doi:10.1029/97JA00562, 1997.

Ouellette, J. E., Lyon, J. G., Brambles, O. J., Zhang, B., and Lotko, W.: The effects of plasmaspheric plumes on dayside reconnection, J. Geophys. Res. Space Phys., 121, 4111-4118, doi:10.1002/2016JA022597, 2016.

Ridley, A. J., Dodger, A. M., and Liemohn, M. W.: Exploring the efficacy of different electric field models in driving a model of the plasmasphere, J. Geophys. Res. Space Phys., 119, 4621-4638, doi:10.1002/2014JA019836, 2014. 
Sandel, B. R., Goldstein, J., Gallagher, D. L., and Spasojevic, M.: Extreme Ultraviolet Imager observations of the structure and dynamics of the plasmasphere, Space Sci. Rev., 109, 25-46, doi:10.1023/B:SPAC.0000007511.47727.5b, 2003.

Sibanda, P., Moldwin, M. B., Galvan, D. A., Sandel, B. R., and Forrester, T.: Quantifying the azimuthal plasmaspheric density structure and dynamics inferred from IMAGE EUV, J. Geophys. Res., 117, A11204, doi:10.1029/2012JA017522, 2012.

Spasojević, M., Goldstein, J., Carpenter, D. L., Inan, U. S., Sandel, B. R., Moldwin, M. B., and Reinisch, B. W.: Global response of the plasmasphere to a geomagnetic disturbance, J. Geophys. Res., 108, 1340, doi:10.1029/2003JA009987, A9, 2003.

Spasojević, M. and Fuselier, S. A.: Temporal evolution of proton precipitation associated with the plasmaspheric plume, J. Geophys. Res., 114, A12201, doi:10.1029/2009JA014530, 2009.

Steele, D. P. and Cogger, L. L.: Polar patches and the "tongue of ionization", Radio Sci., 31, 667-677, doi:10.1029/96RS00369, 1996.

Su, Y.-J., Borovsky, J. E., Thomsen, M. F., Dubouloz, N., Chandler, M. O., Moore, T. E., and Bouhram, M.: Plasmaspheric material on high-latitude open field lines, J. Geophys. Res., 106, 60856095, doi:10.1029/2000JA003008, 2001a.

Su, Y.-J., Thomsen, M. F., Borovsky, J. E., and Foster, J. C.: A linkage between polar patches and plasmaspheric drainage plumes, Geophys. Res. Lett., 28, 111-113, $2001 \mathrm{~b}$.

Summers, D., Ni, B., Meredith, N. P., Horne, R. B., Thorne, R. M., Moldwin, M. B., and Anderson, R. R.: Electron scattering by whistler-mode ELF hiss in plasmaspheric plumes, J. Geophys. Res., 113, A04219, doi:10.1029/2007JA012678, 2008.

Taylor, H. A., Brinton, H. C., and Deshmukh, A. R.: Observations of irregular structure in thermal ion distributions in the duskside magnetosphere, J. Geophys. Res., 75, 2481-2489, 1970.

Taylor Jr., H. A., Grebowsky, J. M., and Walsh, W. J.: Structured variations of the plasmapause: Evidence of a corotating plasma tail, J. Geophys. Res., 76, 6806-6814, doi:10.1029/JA076i028p06806, 1971.

Thomas, E. G., Baker, J. B. H., Ruohoniemi, J. M., Coster, A. J., and Zhang, S.-R.: The geomagnetic storm time response of GPS total electron content in the North American sector, J. Geophys. Res. Space Phys., 121, 1744-1759, doi:10.1002/2015JA022182, 2016.

Tsurutani, B., Mannucci, A.; Iijima, B., Abdu, M. A., Sobral, J. H. A., Gonzalez, W., Guarnieri, F., Tsuda, T., Saito, A., Yumoto, K., Fejer, B., Fullerrowell, T. J., Kozyra, J., Foster, J. C., Coster, A., and Vasyliunas, V. M.: Global dayside ionospheric uplift and enhancement associated with interplanetary electric fields, J. Geophys. Res., 109, A08302, doi:10.1029/2003JA010342, 2014.

Tu, J.-N., Dhar, M., Song, P., Reinisch, B. W., Green, J. L., Benson, R. F., and Coster, A. J.: Extreme polar cap density enhancements along magnetic field lines during an intense geomagnetic storm, J. Geophys. Res., 112, A05201, doi:10.1029/2006JA012034, 2007.
Walsh, B. M., Phan, T. D., Sibeck, D. G., and Souza, V. M.: The plasmaspheric plume and magnetopause reconnection, Geophys. Res. Lett., 41, 223-228, doi:10.1002/2013GL058802, 2014a.

Walsh, B. M., Foster, J. C., Erickson, P. J., and Sibeck, D. G.: Simultaneous Ground and Space-Based Observations of the Plasmaspheric Plume and Magnetospheric Reconnection, Science, 343/6175, 1122-1125, doi:10.1126/science.1247212, 2014b.

Walsh, B. M., Thomas, E. G., Hwang, K.-J., Baker, J. B. H., Ruohoniemi, J. M., and Bonnell, J. W.: Dense plasma and KelvinHelmholtz waves at Earth's dayside magnetopause, J. Geophys. Res. Space Phys., 120, 5560-5573, doi:10.1002/2015JA021014, 2015.

Yizengaw, E. and Moldwin, M. B.: The altitude extension of the mid-latitude trough and its correlation with plasmapause position, Geophys. Res. Lett., 32, L09105, doi:10.1029/2005GL022854, 2005.

Yizengaw, E., Moldwin, M. B., and Galvan, D. A.: Ionospheric signatures of a plasmaspheric plume over Europe, Geophys. Res. Lett., 33, L17103, doi:10.1029/2006GL026597, 2006.

Yuan, Z., Zhao, L., Xiong, Y., Deng, X., and Wang, J.: Energetic particle precipitation and the influence on the sub-ionosphere in the SED plume during a super geomagnetic storm, J. Geophys. Res., 116, A09317, doi:10.1029/2011JA016821, 2011.

Yuan, Z., Li, M., Xiong, Y., Li, H., Zhou, M., Wang, D., Huang, S., Deng, X., and Wang, J.: Simultaneous observations of precipitating radiation belt electrons and ring current ions associated with the plasmaspheric plume, J. Geophys. Res. Space Phys., 118, 4391-4399, doi:10.1002/jgra.50432, 2013.

Yuan, Z.-G., Deng, X.-H., Zhang, S.-R., Wan, W.-X., and Reinisch, B. W.: $F$ region behavior in the SED plume during a geomagnetic superstorm: A case study, J. Geophys. Res., 114, A08303, doi:10.1029/2008JA013841, 2009.

Zeng, W. and Horwitz, J. L.: Storm enhanced densities (SED) as possible sources for Cleft Ion Fountain dayside ionospheric outflows, Geophys. Res. Lett., 35, L04103, doi:10.1029/2007GL032511, 2008.

Zou, S. and Ridley, A. J.: Modeling of the Evolution of StormEnhanced Density Plume during the 24 to 25 October 2011 Geomagnetic Storm, in: Magnetosphere-Ionosphere Coupling in the Solar System, edited by: Chappell, C. R., Schunk, R. W., Banks, P. M., Burch, J. L., and Thorne, R. M., John Wiley \& Sons, Inc., Hoboken, NJ, USA, doi:10.1002/9781119066880.ch16, 2016.

Zou, S., Ridley, A. J., Moldwin, M. B., Nicolls, M. J., Coster, A. J., Thomas, E. G., and Ruohoniemi, J. M.: Multi-instrument observations of SED during 24-25 October 2011 storm: Implications for SED formation processes, J. Geophys. Res. Space Phys., 118, 7798-7809, doi:10.1002/2013JA018860, 2013.

Zou, S., Moldwin, M. B., Ridley, A. J., Nicolls, M. J., Coster, A. J., Thomas, E. G., and Ruohoniemi, J. M.: On the generation/decay of the storm-enhanced density (SED) plumes: role of the convection flow and field-aligned ion flow, J. Geophys. Res., 119, 543-8559, doi:10.1002/2014JA020408, 2014. 